\title{
PASTURE IMPROVEMENT IN LOW ALTITUDE TUSSOCK AND SCRUB-LAND
}

\author{
H. A. DUFF, formerly Fields Instructor, \\ Department of Agriculture, Dunedin
}

'The tussock grasslands and scrub-infested areas of the South Island vary considerably, according to altitude, climatic factors of rainfall, temperature, and wind, and the influence of mankind. To appreciate fully the theme of this paper a brief description of the locality, soil type, and ecology of the particular district will be helpful in evaluating the problems and the methods adopted to bring about an improvement in fertility and production.

The area known as Traquair, Lee Stream, Wehenga, and Hindon represents some 300,000 acres and is situated 25 to 40 miles by road in a north to north-westerly direction from Dunedin. Broadly speaking it is an inland plateau bounded by the Maungatua Mountains in the south, the Lammermoor Range in the west, Deep Stream in the-north, and the Taieri River and Silver Peak Mountains in the east. Abrupt medium to deep gullies and gorges with extensive flat tops are characteristic of the topography of the country, which in altitude varies from 600 to $1,500 \mathrm{ft}$ above sea level. Shelter trees are restricted to homestead plantings and small shelter belts.

The rainfall of 25 to 30 ins is reasonably well distributed, except that January and February may be dry. Thunderstorms are usual in November/December. Winter begins in May and extends through to September, with frosts of 15 to 20 degrees likely to occur in June, July, and August. Five or six snowfalls in a winter are common and at intervals of 5 to 10 years a severe storm of 18 to 24 ins. of snow can disrupt all communications and cause stock losses.

The main soil type is a yellow brown earth known as Wehenga silt loam, generally with a topsoil of 6 to 10 in, but in places shallow with outcrops of soft rock. The average soil tests from samples taken throughout the area are as follows: $\mathrm{pH}$ 4.9-5.2, calcium O-1.0, phosphate 1 .O-2.8. On the eastern and southern borders of this tussock land, manuka scrub (Leptospermum scoparium), bracken fern (pteridium esculentum), and gorse (Ulex europaeus) have taken control. The soil type varies slightly, being transitional from the Wehenga to a Taioma with patches of Warepa (silt loam). 


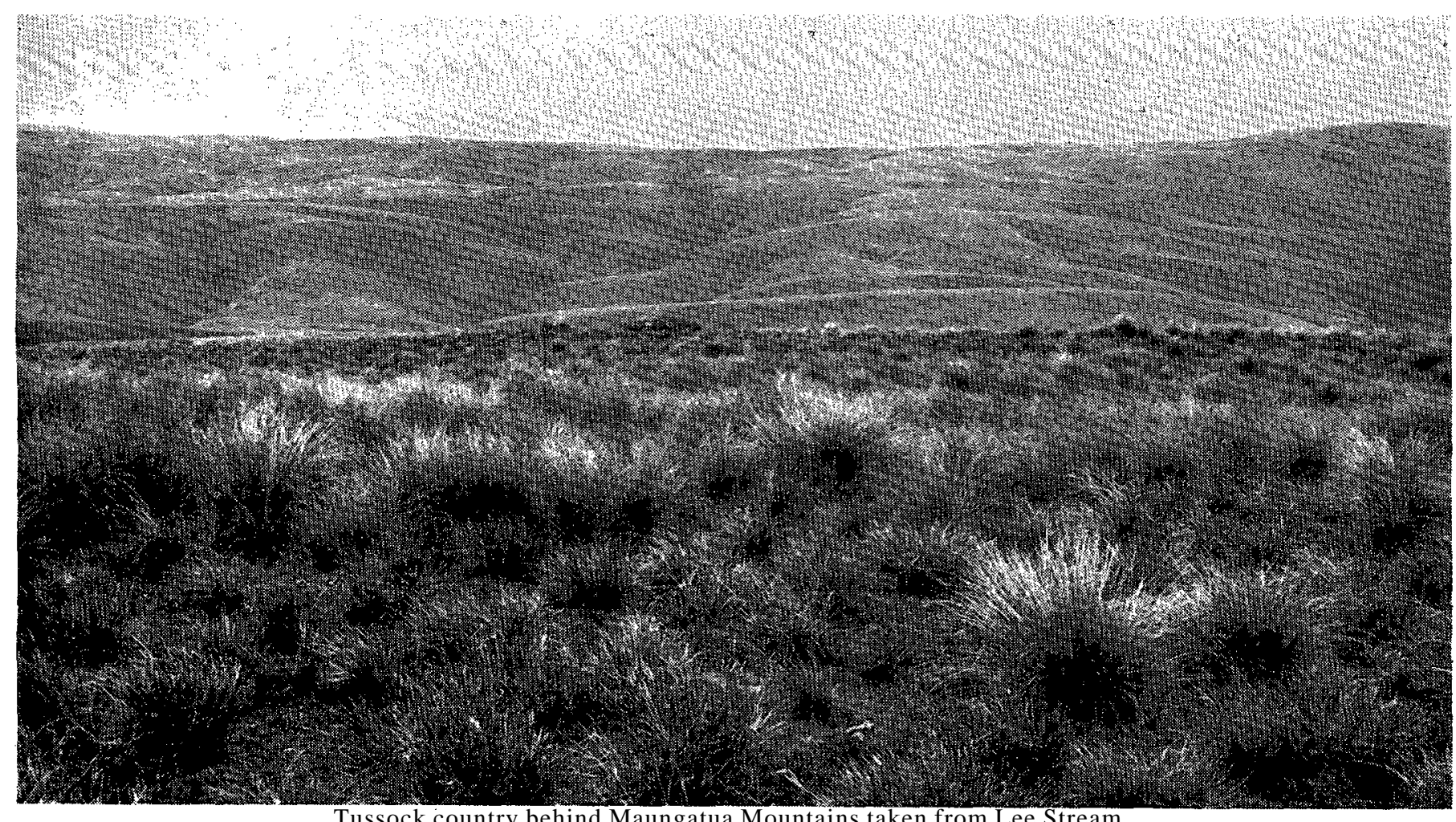

Tussock country behind Maungatua Mountains taken from Lee Stream. 
The vegetation on the areas which have never been ploughed is dominant snow tussock (Danthonia raoullii var. flavescens), fescue tussock (Festuca novaezelandiae), and probably many intermediate forms of these two. Most of the vegetation has been subject to the grazing animal and burning and we find the smaller native plants such as cotton plant (Celmesia spectabilis), snowberry (Gaultheria "antipoda), grass lily (Herpolirion novae-zelandiae), heaths : (Cythodes empetrifolia and Pentachondra pumila), bidi bidi (Acaena nova-zelandiae), and in the more favourable areas the so-called valuable species of blue grass (Agropyron scabrum), blue tussock (Poa colensoi), and silver tussock (Poa caespitosa). Some infestation of browntop has been observed and sweet vernal (Anthoxanthum odorutum) and Yorkshire fog ( $\mathrm{Hol}$ cus lanatus) are to be found throughout the association.

On areas which were ploughed over 60 years ago and cropped with oats to feed horses and bullocks on their way to the goldmining districts in Central Otago, fertility was depleted and browntop, Chewings fescue, and small native herbs predominate. The scrubland belt is dominant red manuka (Leptospermum scoparium), bracken fern (Pteridium esculentum), gorse ( Ulex europaeus), with some tutu (Coriaria sarmenthosa) and many other less important species.

The stock carrying capacity of these tussock grasslands is 1 ewe to 3 acres with the more depleted country probably much the same but decreasing to 1 ewe to 6 acres. Lambing is approximately 70 per cent with wool returns of $6 \frac{1}{2}$ to $7 \mathrm{lb}$ from dominant Romney cross ewes.

This introduction will assist in an understanding of the problems to be solved in improving this low altitude tussock and scrub land.

\section{Efforts to, Solve Problems}

The main problems to solve were those of low fertility and infestation by unproductive grass species and manuka. Drainage was generally not necessary and supplies of water for stock and man were adequate. The first essential to successful development of this country; was to find out how it could be made to grow crops and high-producing pastures. Some 15 to 20 years ago was

$*$ the commencement of what has grown into a concerted and cooperative effort'by farmers and the Department of Agriculture to

"find solutions" to the problems of the area. Though some are

: solved; much remains to be done, but there is sufficient evidence to prove that properties can be developed and production increased by as much as 8 to 10 times.

The first phase was to investigate the value of various grass and clover species, lucerne, chicory, lime, and phosphatic fertili- 
sers. This was closely followed by work with trace elements such as boron, zinc, vanadium, molybdenum, magnesium, manganese, and casting worms. The use of superphosphate, molybdenum, and worms gave promising results. However, as these were successful only on certain areas where cultivation could be carried out, it was realised that something more was required to speed up the work and increase production economically. Further experiments and observation seemed to indicate that aerial sowing of clovers was not successful and the Blackmore tips as a means of introducing clovers to the existing sward were tried by a farmer. Success was only partially achieved and there was no real confidence in the method. The Australian sod-seeder was first used in this area, but was not an outstanding success. The next phase of the work was the real turning point. This was experimental evidence which proved that inoculation of clovers was essential if the tussock grassland was to be improved without cultivation; and it was, and is, considered that this is essential. With this evidence and subsequent co-operating farmers' experience, it has been established that with ample reverted superphosphate (3, cwt per acre), molybdenum, and clover inoculation, successful establishment of clovers can be achieved on existing tussock grassland.

A year later (1955) interest was taken in the possibility of using the roller drill to cut costs of pasture seed mixtures normally sown at 38 to $42 \mathrm{lb}$ per acre. Today with the use of this machine 22 to $24 \mathrm{lb}$ of a grass and clover mixture is all that need be sown. By error $12 \mathrm{lb}$ per acre were once sown and even this gave a satisfactory sward.

Another of the notable successes in this area has been the sowing down to permanent pasture (300 to 400 acres by one farmer) of land which had been cultivated but not put through a root crop, which is normally considered essential for successful establishment of pastures. One of the principal reasons for this is the use of inoculated clovers.

I mentioned before that casting worms (Allolobophora caliginosa) were tried. Results were very slow and it was some 5 years after their introduction before results were apparent, but they did eventualy show over 70 per cent increase in spring production of pasture. Farmers are convinced that they arc worthwhile and have transplanted worms into various parts of their properties.

Now, what about lime? It has been a point of argument wherever men with an agricultural background have congregated. Before the use of molybdenum it was considered that 3 to 4 tons of lime per acre were required. When molybdenum was proved to give results $1 \frac{1}{2}$ tons was thought sufficient. During the last 3 to 4 years, co-operative trials with farmers have given some interesting 


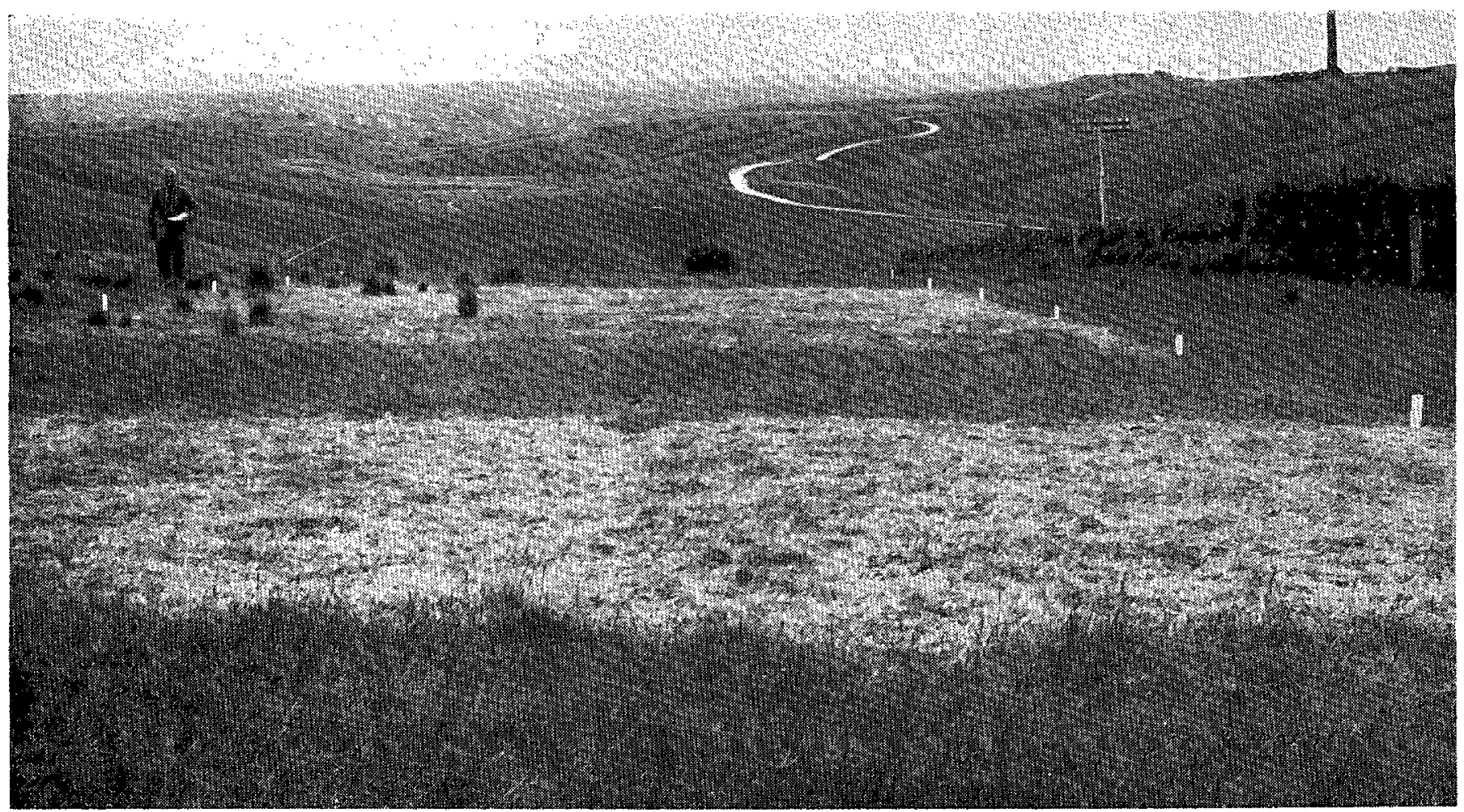

W. J. Reid \& Sons' property, "Traquair", showing typical tussock country in background and trial area in foreground. 
information. Remember that earlier in this paper I mentioned that the $\mathrm{pH}$ was 4.9 with a calcium level of $\mathrm{O}-1$. This surely is an indication that $1 \frac{1}{2}$ to 2 tons per acre is required. We definitely need lime, but results to date suggest that for at least the first 3 years of development 5 to $10 \mathrm{cwt}$ per acre may be adequate. This is definitely so if the land is not ploughed. This low rate of liming is important in that it keeps down the initial cost of development. If it is later found necessary to apply more lime to maintain production, it should be possible to do it out of income rather than with borrowed capital.

The points I have mentioned so far in this paper apply particularly to the tussock country or reverted pasture in this area, but I see no reason why they should not have some application to most of the 1,000,000 acres of undeveloped country in Otago and Southland. Where the land is carrying white clover the answer would probably be only superphosphate and possibly molybdenum, but the areas I refer to are generally devoid of legumes and therefore have presented their own problems.

The usual district practice of increasing production has been what one may term conventional. Where the winters are hard and it is desirable to provide supplementary feed for young sheep it is usual to plough an area and allow 6 to 12 months of a fallow. Spring cultivation, liming, and ridging swedes and/or turnips have given from poor to good crops for winter feed. Often a similar crop the following year again gives variable results, but poor results are attributable to poor cultivation, and diseases such as dry rot and mosaic rather than low fertility. After these supplementary crops the areas are sown down to permanent pasture. The greatest menace to these pastures is the porina caterpillar, which is successfully controlled by $2 \frac{i}{2}$ lb of 100 per cent p.p.i. D.D.T. per acre. These pastures have lasted as long as 18 years and promise to maintain good production for some years, yet with an average carrying capacity of 23 to 3 sheep per acre. Hay crops of Montgomery clover yielding up to 80 to 100 bales per acre are common on second-year pasture, but thereafter cocksfoot and white clover tend to provide the bulk of the production, although Montgomery is known to last 5 to 6 years.

\section{Scrubland}

This then is the story of the pasture improvement of this tussock grassland and the previously cropped-out reverted areas in the districts concerned, but it would not be complete without reference to the bordering country which has reverted to manuka after being overcropped with cereals in the early days of colonisation and up to about the 1920's. 
Two methods of developing this scrubland have been used. The first one is the conventional method of ploughing with heavy swamp ploughs, cultivation, liming at $30 \mathrm{cwt}$ per acre- 1 consider 1 ton would be ample-and ridging swedes at 11 to $13 \mathrm{oz}$ to the acre with 3 to $4 \mathrm{cwt}$ of molybdenised reverted superphosphate, or turnip mixture. If more acreage than is required for winter feed can be handled in any one year, it is sown down to pasture, using the roller drill and 22 to $24 \mathrm{lb}$ of a pasture seed mixture plus $3 \mathrm{cwt}$ of molybdenised superphosphate per acre. The cost of this development has been estimated to be $£ 22$ to $£ 24$ per acre.

The second method is to use a large roller and heavy crawler 'tractor to roll the scrub in the summer and winter. In the spring when 'a light nor'-westerly wind is blowing the rolled scrub is 'burnt. This is followed immediately by aerial sowing of 2 cwt of molybdenised reverted superphosphate per acre with a seed mixture -containing $2 \mathrm{lb}$ of white clover, $3 \mathrm{lb}$ of Montgomery clover, $4 \mathrm{lb}$ : of ryegrass (short-rotation), $4 \mathrm{lb}$ of cocksfoot, and $1 \mathrm{lb}$ of dogstail. The use of inoculated clover ensures a good strike of healthy, vigorous plants. Although much large manuka not totally burnt remains, lime at 1 ton per acre is spread by bulk topdresser. it is essential for the trucks to travel in the same direction as the thactor -and roller.

jn? two years, 1,200 acres of a 2,000-acre block have been developed in this way and the results to date are considered most satisfactory. The clovers established fairly well, but it was not until the second year that results were proved beyond expectations. The. Montgomery clover grew to 18 to 24 in and in gullies overtopped bracken fern and climbed up manuka bushes. The grasses which it had been diffieult to find in the first year must have struck, because cocksfoot and ryegrass were easily seen and contributed a fair -amount of the feed in the second summer and autumn. The cost of this development is estimated to be $£ 10$ per acre and the stocking rate has been increased from 1 sheep to 10 acres to nearly 1 sheep per acre in 1957. Total number of stock increased from 500 to 1,000 in one year. The success of this method-and in my mind there is no doubt about it-is dependent on the ability of the farmer to manage his stock grazing programme. Too lenient or too hard grazing at the wrong time can cause failure or part -failure of this particular method of land improvement. This is only the commencement of the programme and problems in the future will have to be decided at the time. However, in broad principle the policy of a fertility build-up before endeavouring to cultivate and grow crops is the theme on this particular property and there are many thousands of acres of similar 


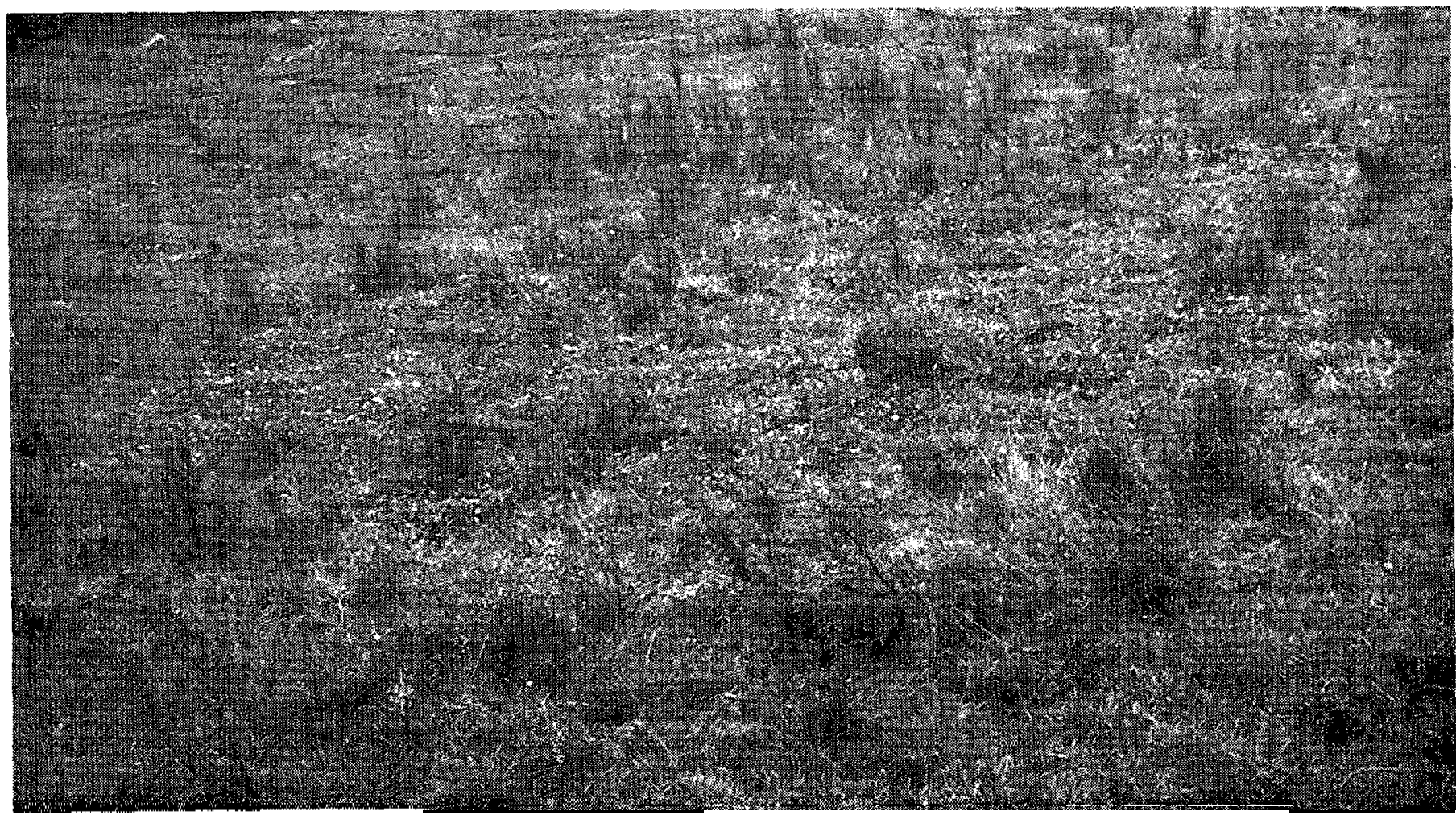

Thornton and Johnstone's property. Scrub country rolled and burnt. First stage of development before aerial sowing of inoculated clovers, grâss seed, and fertiliser. 
country where it is considered this method could be both successful and economic.

\section{$\mathrm{N}$ ew $\mathrm{M}$ ethods Being Tried}

In the last two years the chemical dalapon has been used successfully in the North Island to kill the existing browntop sward, thus allowing oversown species capable of high production to establish and grow satisfactorily. Also in the nassella country of North Canterbury dalapon has been a very successful aid in controlling this problem grass.

Trials were laid down in the late winter of 1957 on both the reverted tussock grassland and the scrub-infested areas. Comparisons using dalapon at $2 \frac{1}{2}$ and $5 \mathrm{lb}$ per acre with and without A.T.A. at, $1 \mathrm{lb}$ per acre and 2,4,5-T at $2 \mathrm{lb}$ acid equivalent per acre hạve been tried. Lime, fertiliser, clovers, and a grass mixture were oversown one month after the application of the chemicals. To date the results are not encouraging and farmers should not rely on this method at present.

The costs of this method in relation to results to date do not make it a worthwhile proposition.

The use of lime-pelleted clover seed for oversowing is under investigation and after one year does not promise to have any advantage over unpelleted seed. It is essential of course to inoculate to ensure a good strike and establish vigorous seedlings to compete with the existing plant association.

\section{Summary and Conclusion}

In this story of land development we have at least four possible methods that can be used together or singly, depending on the economic and physical structure of a particular farm.

1. Conventional (ploughing and cultivating as generally accepted) .

2. Broadcasting inoculated clover and grass seeds.

3. Rolling and burning scrub followed by oversowing.

4. Chemical farming; doubtful at this stage, but could have a future.

Before concluding I want to thank the co-operating farmers, research workers: and extension officers for their co-operation during the years we worked together on the problem. I cannot let this opportunity go by without asking two questions: "When do westop?";" and "Where are we going?"

The individual farmer as well as the research and extension worker must ponder these questions before it is too late. This applies particularly to the tussock grasslands, because in this area 
unless we plant trees to protect our improved pasture and/or reserve our tussock we may not economically win the battle with nature of stock losses and soil erosion.

\section{DISCUSSION}

Q. (S. H. Saxby): Following burning and oversowing of scrubland, is there much re-establishment of the manuka?

A. There is regrowth and seedling manuka present, but in this method of rapid fertility build up, it has not been a serious problem.

Q. (W. Faithful): What grasses have been found most suitable in association with the legumes?

A. No detailed studies have been made, but observation suggests that cocksfoot and short rotation ryegrass are most valuable. A suitable mixture would be 4-6 lb short rotation, $3 \mathrm{lb}$ cocksfoot, $1 \mathrm{lb}$ crested dogstail, $2 \mathrm{lb}$ white and $2 \mathrm{lb}$ Montgomery red clover per acre.

Q. (Dr P. D. Sears): What is the value of lime for encouraging numbers and activity of casting worms?

A. When the casting-worm trial was laid down, soil fertility and $\mathrm{pH}$ were not considered. The low $\mathrm{pH}$ may have accounted for the very slow initial spread of the worms.

Q. (W. Elliot): Has any work been done on improving the productivity of sweet vernal and Yorkshire fog by clover oversowing and management?

A. No measurements have been made, but it is known that these species can play a more useful part when associated with a vigorous legume, and properly managed.

Q. (E. Watt): What have been your experiences with lucerne, both erect and prostrate types, in this area?

A. A number of lucerne types have been tried, but with little success. Sometimes a reasonable stand is obtained but it lasts only 4-5 years.

Comment: R. C. Schofield: On soils of similar pH, in Central Otago, greenfeed has been found of value as a precursor to lucerne.

Q. (J. E. Bell): What has been done with the different soil types, at the various pH's, to examine the lime molybdenum interactions?

A. One small factorial trial was laid down, but this was in the nature of a pilot experiment, and it has not been followed up. 